\title{
Drawing with words
}

\author{
Philip Tyler \\ University of Brighton
}

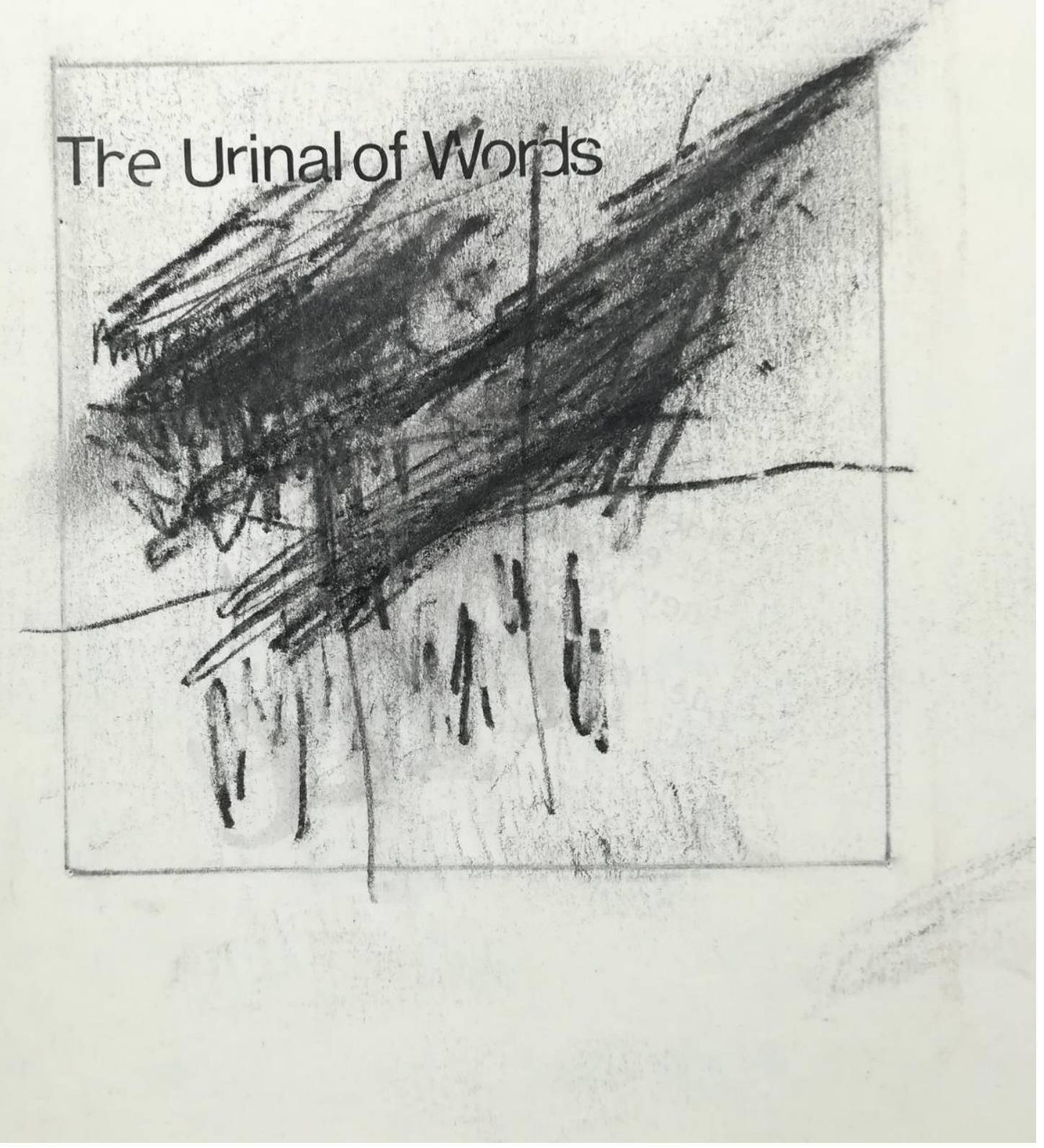

When I completed my MA, I found myself at crisis point. What was I doing? What was my work about?

I had realised that I had spent seven years in the pursuit of style with no content whatsoever. My work had evolved from figuration through gestural abstraction toward a minimalist aesthetic over that time. Rectangles of colour were based on mathematical division of the square, quarter squares 
were juxtaposed against one and a quarter squares of layered colour. I was seeking a kind of sensate experience and it seemed that I had achieved something, which, on the face of it, looked like art, or rather looked like the art that I had admired (Ryman, Reinhardt, Smith and Kelly), but lacked any kind of content or meaning.

Had this last seven years been a waste of time. I found myself empty, devoid of inspiration, bleak, introspective. At that time I was commuting every day from Brighton to London, 20 hours a week on a train, tired all the time, hardly able to make use of what free time I had. Faced with this predicament the train became my studio, my sketchbook a thinking tool. If indeed I felt completely empty, with no ideas whatsoever, then the idea of no ideas became the topic of my drawing exploration.

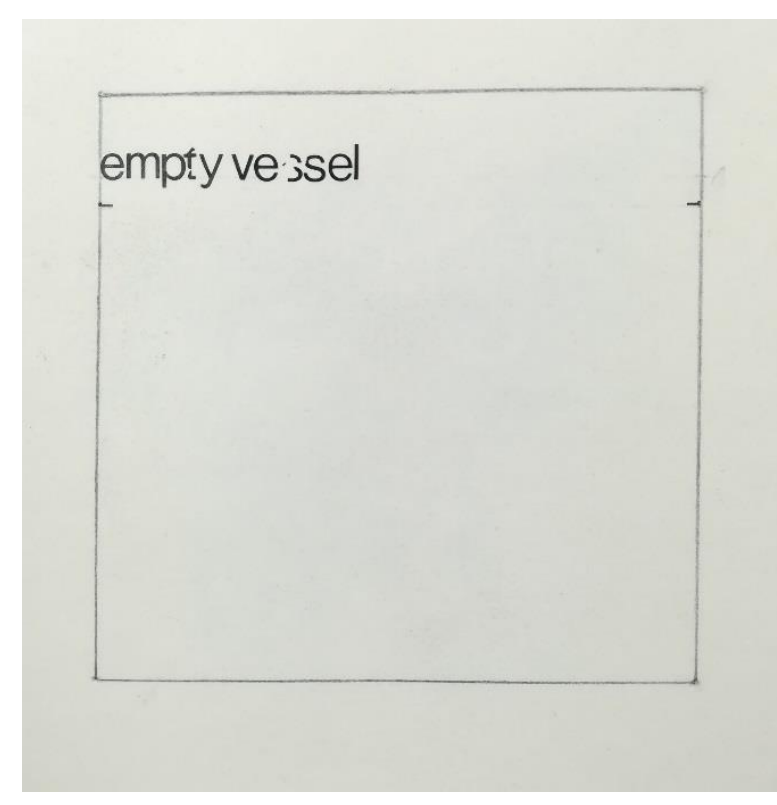

A small A6 hard back sketchbook, I drew a $5 \mathrm{~cm}$ square in the middle of each page. What would go inside? Nothing, emptiness, I felt completely barren, yet this idea seems to provoke and action a word a written word scribbled.

Words contain meaning, if indeed my work was about nothing, then by writing the meaning of the work I was putting meaning in. The writing became confessional, my inner feeling and thoughts so personal that to expose myself to the world was to leave me more vulnerable, so the letter forms became disguised as marks on the paper, scribbled and dashed impossible to decipher. The act of drawing a catharsis. Tiny little sentences grew into narratives, frustrations about my predicament, anger made way to possibilities became my discussion points with myself. 


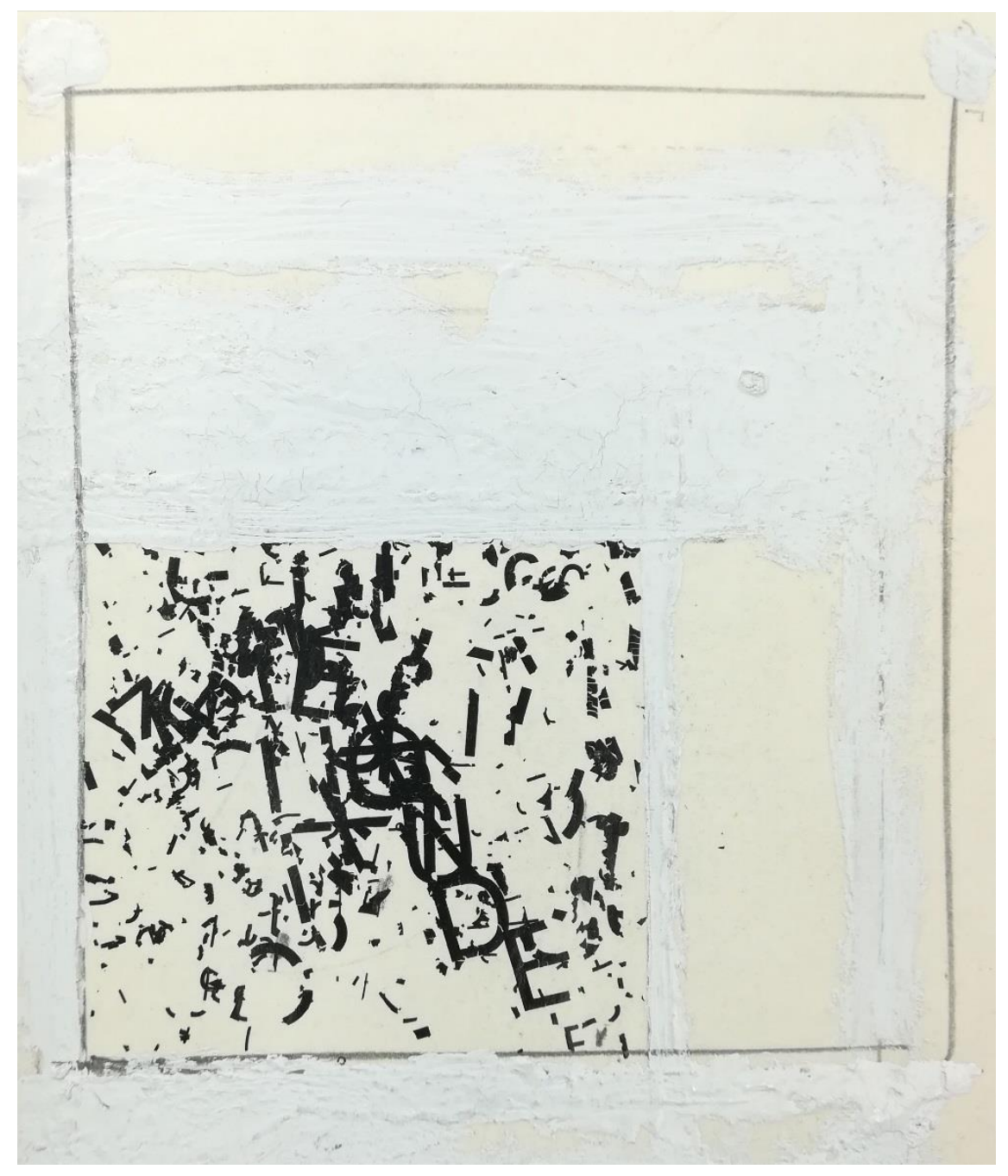

I used carbon paper in between my sketchbook pages. As I made one drawing, I left the trace of my mark on another, so that when I turned over the page I had a starting point for the next drawing another and another. I began to explore the possibilities of tiny Letraset letters, rubbing the letters but moving it at the same time so that letter forms themselves corroded and decayed. Words lost their meaning. If indeed I felt confused and lost, then the text would describe that feeling, that sense of not knowing.

I was interested in the grid, the square and the divisions of that form to find subtle nuances of shape. The grid, once again, informed these explorations, sometimes cutting up and rearranging images sometimes mapping out and then cancelling with the use of white Tipp-Ex removing meaning. Over the course of a year and three sketchbooks later, gradually motifs began to form, a figure, a tree, a door and a ladder.

At that time I wrote a statement for an exhibition (I was in East at Norwich school of Art) "To deify the aesthetic is to seek revelation in emptiness, to create a false prophet". I was on the cusp of my work changing, to see beyond the simple idea of making work, which looked like art and to start making work about my experience of being in the world.

The minimalist paintings and prints I had made during my MA became the support onto which new drawings and paintings were made. I painted gestural trees, evocative of memory, of time and of place, totemic objects that seemed to hold meaning for me. These trees became luminous, fiery explosive gestures of paint. I used gold and copper paint to increase their luminescent quality, I wrote words on the paintings, to make more explicit the meaning I wanted to achieve. Colour 
became a much more significant element to these pieces, layered mixed media imagery to build up a depth of space and light.

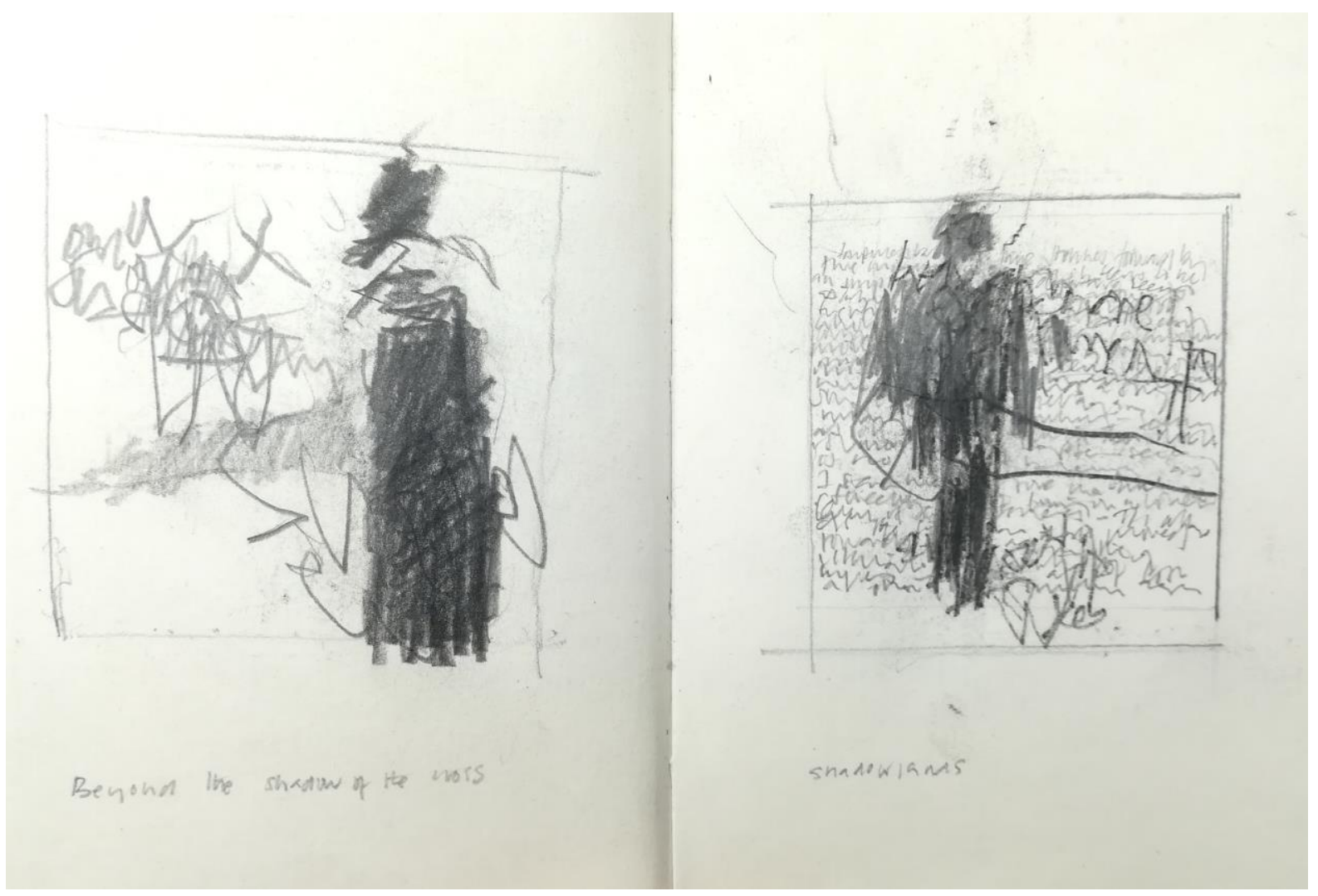

Gradually a figure became to emerge out of this landscape. A figure, which grew in scale and complexity. The figure was finding a way through the landscape, seeking to find themselves in the confusion of works and images. How should be drawn, what would his role be, what did he have to say?

Twenty-five years have passed since that time, and I continue to make drawings. My sketchbook is still my thinking tool and it is where my ideas are resolved. As an artist, I am interested in drawing as a mimetic activity, recording what I see in front of me, whether some landscape of figure in repose. As an educationist, I am interested in the way that informs practice. the interrelationship between 2D and 3D, visual perception as a mechanism to change how we see to make more objective our vision of it. Blind drawing, gesture drawing, drawing fragments, simplification, basic shape, spatial drawing, process drawing and systems based drawing

"Drawing with and without words, or drawing in 3D with paper, tape or wire and other mediums, which all have their own potential. If indeed my drawing activity back then, helped me out of this dilemma, then drawing becomes part of a process: My work is no longer concerned with the aesthetic. If anything, it has become much more figurative and I work within the traditional genres of landscape, the still life and the figure. Mark making and colour are still important and so too the square and formal awareness of the image, but this series of drawings not only served as a place to vent my anger, a catharsis and a space to expel my demons, it was a place of dialogue and confession. Only by putting all my ideas on paper was I able to see clearly a direction to follow. 